Article

\title{
Control Strategies of Full-Voltage to Half-Voltage Operation for LCC and Hybrid LCC/MMC based UHVDC Systems
}

\author{
Gen Li ${ }^{1}{ }^{\mathbb{C}}$, Wei Liu ${ }^{1, *}$, Tibin Joseph ${ }^{1}{ }^{\mathbb{C}}$, Jun Liang ${ }^{1, *}$, Ting An ${ }^{2}$, Jingjing Lu ${ }^{2}$, \\ Marcio Szechtman ${ }^{3}$, Bjarne Andersen ${ }^{4}$ and Qikai Zhuang ${ }^{5}$ \\ 1 School of Engineering, Cardiff University, Cardiff CF24 3AA, UK; LiG9@cardiff.ac.uk (G.L.); \\ JosephT@cardiff.ac.uk (T.J.) \\ 2 Global Energy Interconnection Research Institute, Beijing 102211, China; anting@geiri.sgcc.com.cn (T.A.); \\ lujingjing2014@126.com (J.L.) \\ 3 Eletrobras Cepel, Rio de Janeiro 26053-121, Brazil; marcio@szechtman.net \\ 4 Andersen Power Electronic Solutions, Bexhill-On-Sea TN39 4QL, UK; bjarne@andersenpes.com \\ 5 Global Energy Interconnection Research Institute Europe GmbH, Kantstr, 162 Berlin, Germany; \\ zhuangqikai@gmail.com \\ * Correspondence: LiuW28@cardiff.ac.uk (W.L.); LiangJ1@cardiff.ac.uk (J.L.)
}

Received: 17 January 2019; Accepted: 20 February 2019; Published: 23 February 2019

\begin{abstract}
With the increasing demand of transmitting bulk-power over long-distance, the ultra high-voltage direct-current (UHVDC) transmission systems become an attractive option. Nowadays, not only the line commutated converter (LCC) based systems, but also the modular multilevel converter (MMC) based systems have reached UHVDC levels. The converter stations of UHVDC systems normally utilize two series-connected valve-groups to reduce the difficulties of device manufacturing and transportation. This high-voltage and low-voltage valve-group configuration allows the UHVDC systems to achieve a full-voltage to half-voltage operation which increases the flexibility of the systems. However, the existing research only focuses on the full-voltage to half-voltage control of LCC-UHVDC systems. The control strategies for hybrid LCC/MMC UHVDC systems are underresearched. Moreover, the approaches to reduce the load-shedding caused by the full-voltage to half-voltage control for both LCC and hybrid LCC/MMC based UHVDC systems have not been investigated. In this paper, full-voltage to half-voltage control strategies for both LCC and hybrid LCC/MMC based UHVDC systems have been proposed. Moreover, to avoid load-shedding caused by the half-voltage operation, a power rescheduling method that re-sets the power references of the half-voltage operating and full-voltage operating poles has been proposed. The proposed full-voltage to half-voltage control strategies and power rescheduling method can achieve a stable and fast control process with a minimum power loss. The proposed methods have been verified through the time-domain simulations conducted in PSCAD/EMTDC.
\end{abstract}

Keywords: UHVDC; line commutated converter; modular multilevel converter; hybrid LCC/VSC; power rescheduling; half-voltage operation; valve bypassing

\section{Introduction}

To achieve the targets of sustainable development and copying with climate change, developing renewable energy has been widely recognized as a key solution. However, large-scale renewable power resources are usually remotely located from load centers [1-3]. This increases the utilization of high-voltage direct-current (HVDC) technology which is a feasible and efficient option to transmit large-scale renewable power over long distances [4-6]. 
HVDC transmission systems can be implemented using the line commutated converter (LCC) or the voltage source converter (VSC). The LCC-HVDC technology has developed to a high degree of maturity in the past decades. For instance, the China State Grid's Changji-Guquan ultra HVDC (UHVDC) link has reached to $\pm 1100 \mathrm{kV}$ with a capacity of $12 \mathrm{GW}$ [7]. However, the LCC-based technology still exhibits some limitations such as commutation failure, no active and reactive independent control, the need of large ac filters, and the requirement of connecting to stiff ac grids $[4,6]$.

The modular multilevel converter (MMC), a type of VSC, is becoming a preferred topology for HVDC transmission due to its significant features, such as compact and scalable system design, no commutation failure, and operation with weak ac grids [8-10]. Moreover, with the fast development in the past two decades, the converter capacity and voltage level of MMC-HVDC technology have also been achieved in UHVDC levels [11,12]. This makes the hybrid DC transmission systems which utilize both LCCs and MMCs in UHVDC applications become possible.

The hybrid LCC/MMC HVDC systems provide an effective option to complement the advantages of the two technologies. It can not only improve power supply security by eliminating commutation failure, but also reduce the overall system power losses and capital cost [13-16]. The first hybrid LCC /MMC UHVDC project in the world is the $\pm 800 \mathrm{kV}$ Kun-Liu-Long three-terminal network $[17,18]$. It consists of one LCC as the rectifier and two full-bridge (FB) MMCs as the inverters.

Considering the equipment design and transportation limitations, the design of both LCC and LCC/MMC UHVDC systems adopt the scheme of using two series connected valve-groups in each pole $[19,20]$. High speed bypass switches are equipped on the DC terminal of each valve-group to bypass the valve-groups that need to be maintained or the valve-groups suffering component failure or faults [21-23]. The bipolar configurations of UHVDC links enable them to achieve some flexible operation modes. For instance, the mode in which one pole is in half-voltage operation and the other pole is in full-voltage operation. This mode can be achieved by bypassing one valve-group in one pole. The half-voltage pole can keep transmitting power without affecting the full-voltage operating pole. This will reduce the power loss caused by converter maintenance or component failure and, therefore, mitigate the negative impact of load-shedding on the AC grid's operation. However, control strategies of full-voltage to half-voltage operation should be properly designed to make sure the process is smooth and will not cause transient overvoltage and overcurrent.

Reference [22] investigates fault protection methods in LCC HVDC systems using bypass valves. However, it does not consider the full-voltage to half-voltage operation and control. In [24,25], valve-group bypassing strategies of LCC-UHVDC systems have proposed. However, they have not provided methods to minimize the load-shedding when one pole gets into the half-voltage operating mode. In addition, they have not considered the control strategies for hybrid LCC/MMC UHVDC systems. The capability of the reduced-DC-voltage operation in a hybrid LCC/MMC UHVDC system is presented in [18]. However, a detailed control strategy has not been provided. Moreover, the studies in [18] only consider the full-bridge MMC (FB-MMC) based systems while the half-bridge MMC (HB-MMC) based systems have not been investigated. As the converter configurations of HB-MMCs and FB-MMCs are different, the control strategies of their full-voltage to half-voltage operation are different as well. Therefore, different control strategies are needed for the two types of MMCs.

In this paper, the capability and flexibility of full-voltage to half-voltage operation in LCC and hybrid LCC/MMC UHVDC systems are discussed and summarized. According to the characteristics of LCCs and MMCs, different control strategies for full-voltage to half-voltage operation for LCC and hybrid LCC/MMC UHVDC have been proposed. In additional, in order to reduce the power loss during the half-voltage operation, a power reschedule strategy is proposed by re-setting the power references of the half-voltage operating and full-voltage operating poles based on their pre-change power references. The proposed full-voltage to half-voltage control strategies and the power reschedule strategy have been verified in LCC and hybrid LCC/MMC UHVDC systems built in PSCAD/EMTDC. 


\section{Converter Station Configurations of UHVDC Systems}

In this section, the converter station configurations and possible operation modes of the LCC and hybrid LCC/MMC UHVDC systems are discussed. In LCC-UHVDC systems, the converters in each pole are typically built with two series-connected valve-groups, as shown in Figure 1. For the positive pole, the low-voltage (LV) valve-group is the one connecting to the ground and the high-voltage (HV) valve-group is the one connecting to the DC line. Each of the HV and LV valve-groups is a 12-pulse LCC [21], as shown in the figure. Therefore, the whole converter in each pole is a 24-pulse LCC.

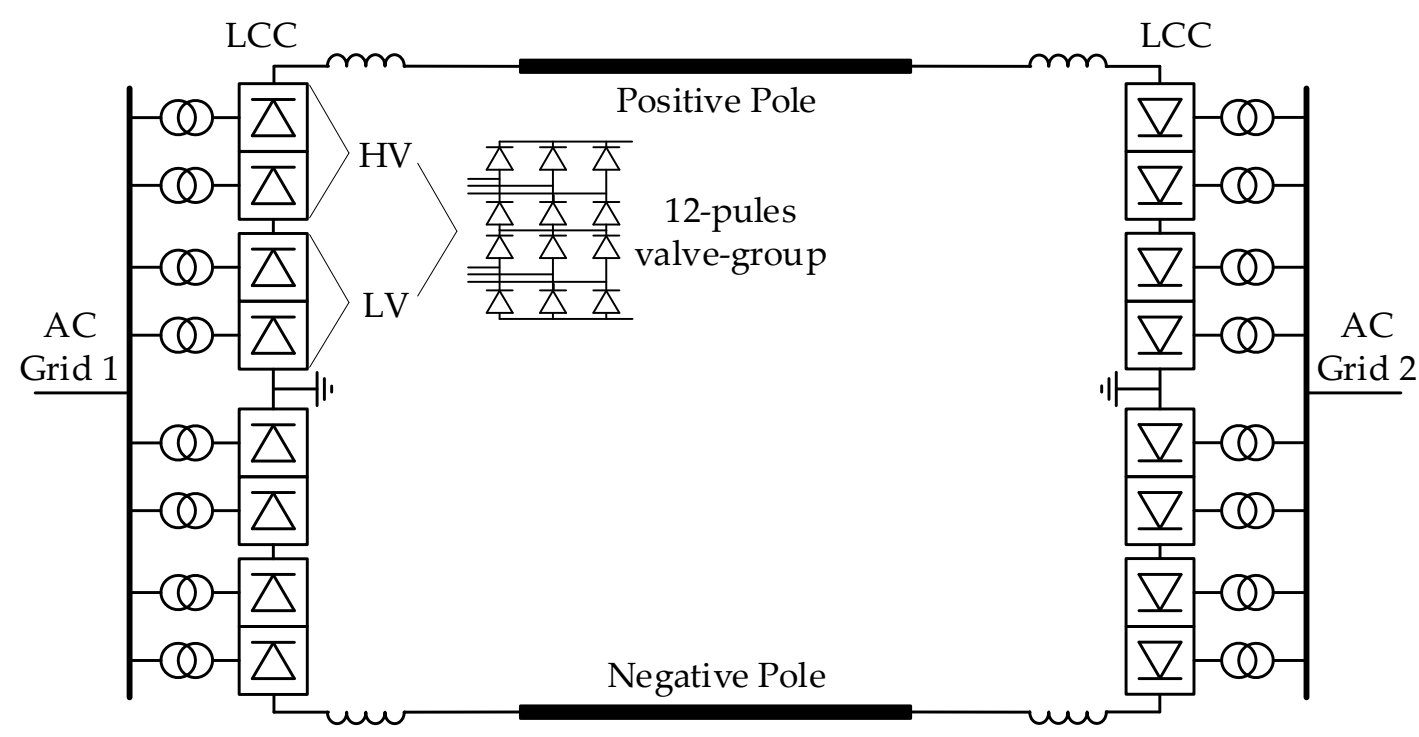

Figure 1. A typical line commuted converter (LCC) ultra high-voltage direct-current (UHVDC) system.

Figure 2 shows a hybrid LCC/MMC UHVDC system. In this system, the LCC operates as the rectifier and the MMC operates as the inverter. This topology will not have the problem of commutation failure. The MMC station also consists of HV and LV MMC bridges, as shown in Figure 2.

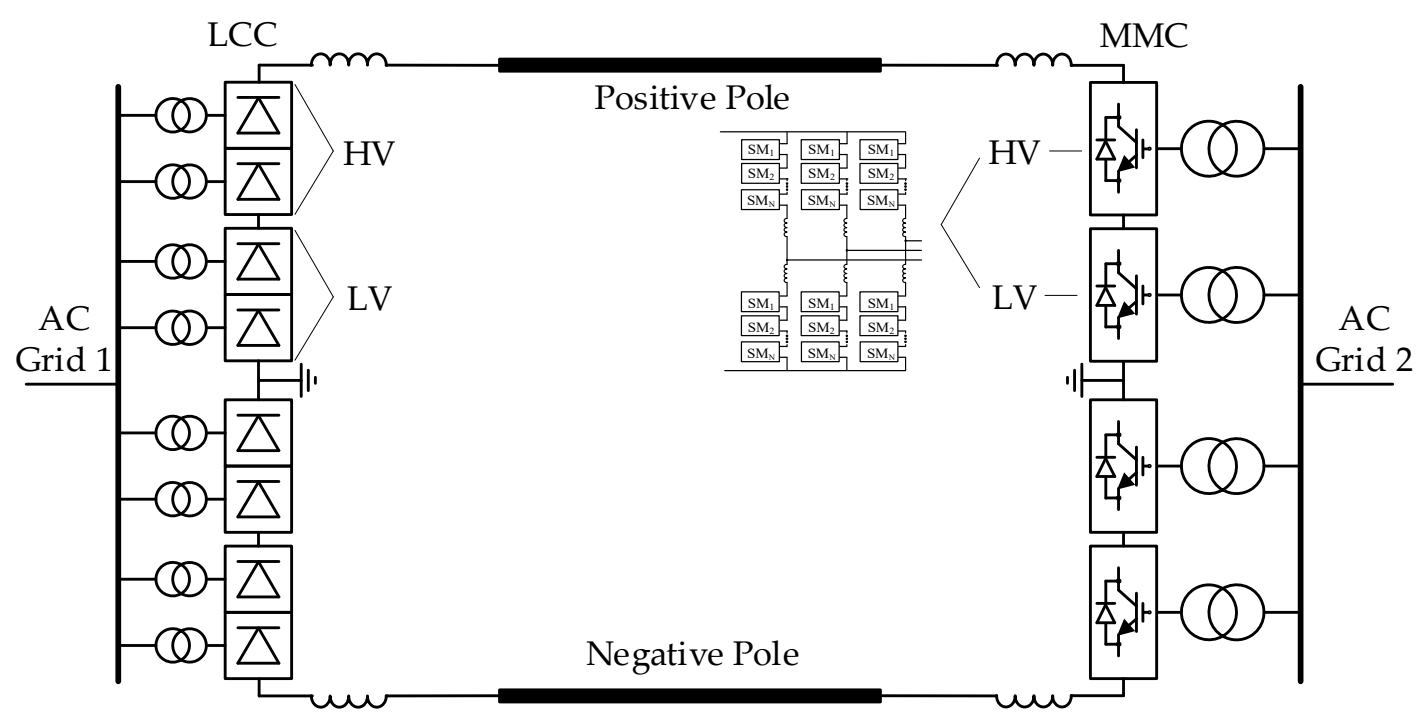

Figure 2. A hybrid LCC/modular multilevel converter (MMC) UHVDC system.

There will be circumstances that partial valve-groups have to be bypassed when there are failures of components or a scheduled maintenance. Each valve-group in the above systems can operate independently. The system can achieve different operating modes with the help of the DC side bypass switch (BPS) and the isolators equipped with each valve-group, as shown in Figure 3. 


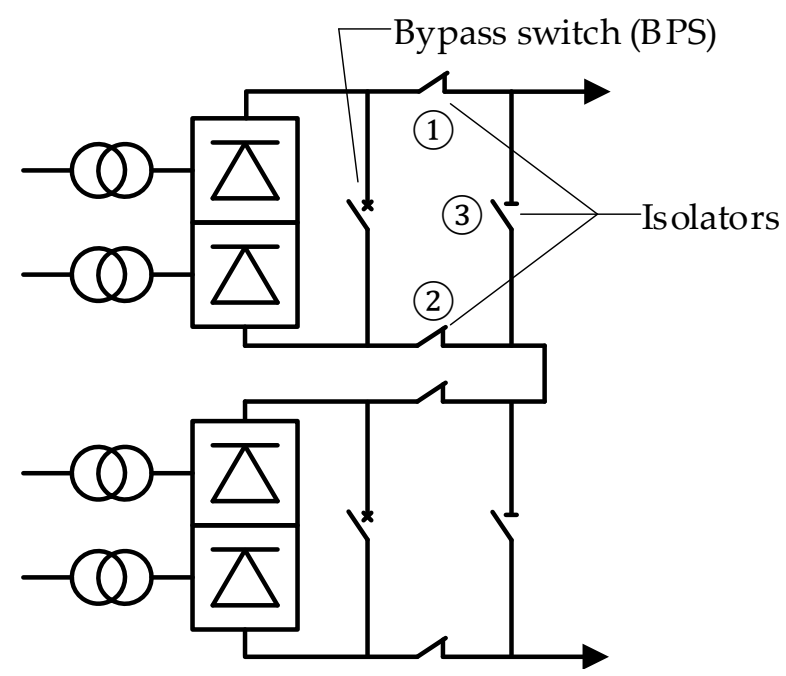

Figure 3. The bypass switches and isolators equipped with the valve-groups.

The high-speed BPS is to bypass the valve-group and provide current paths during the bypassing process. The valve-group isolators (1) and (2) are to isolate the valve-group from the DC line when the bypass process is completed. Then the current will flow through the bypass isolator (3). With this configuration, a bipolar UHVDC transmission system has the following operating modes [21,24]:

(1) Normal operation: both poles are in full-voltage operation; the whole system power capacity is $100 \%$;

(2) Partial monopole off: one-pole is in full-voltage operation while the other is partially off ( $25 \%$ of the rated capacity); the whole system power capacity is $75 \%$;

(3) Monopole off: one-pole is in full-voltage operation while the other is off; the whole system power capacity is $50 \%$;

(4) Partial bipole off:

a. Both poles are in (half-voltage operation) partial monopole off (each pole has $25 \%$ of the rated capacity); the whole system power capacity is $50 \%$;

b. One-pole is off while the other is (half-voltage operation) partial monopole off ( $25 \%$ of the rated capacity); the whole system power capacity is $25 \%$;

(5) Bipole off: the whole system is shut down; the system power capacity of the whole system is 0 .

Figure 4 shows several possible operating modes of the positive pole of an LCC-UHVDC system. Mode (a) is in normal (full-voltage) operation. Modes (b)-(d) are in partial monopole operation: (b) the LV valve-group is bypassed, (c) the HV valve-group is bypassed, (d) mixed HV and LV valve-groups operation. The voltage in the modes (b)-(d) is half of the rated DC voltage. The process of changing the operating mode from mode (a) to modes (b)-(d) is called full-voltage to half-voltage operation in this paper.

In order to achieve a fast and stable full-voltage to half-voltage process, control strategies should be designed properly with the consideration of the different characteristics of LCCs and MMCs. The control strategies need to avoid generating large transient overvoltage and overcurrent during the full-voltage to half-voltage process and to reduce the power loss after completing the half-voltage operation. 


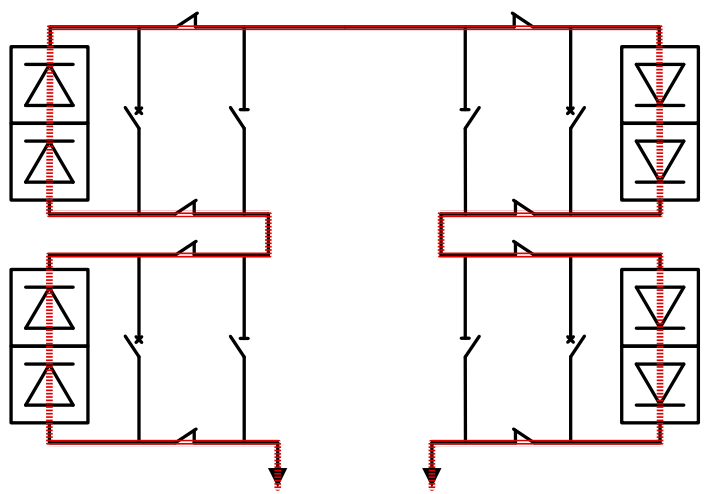

(a)

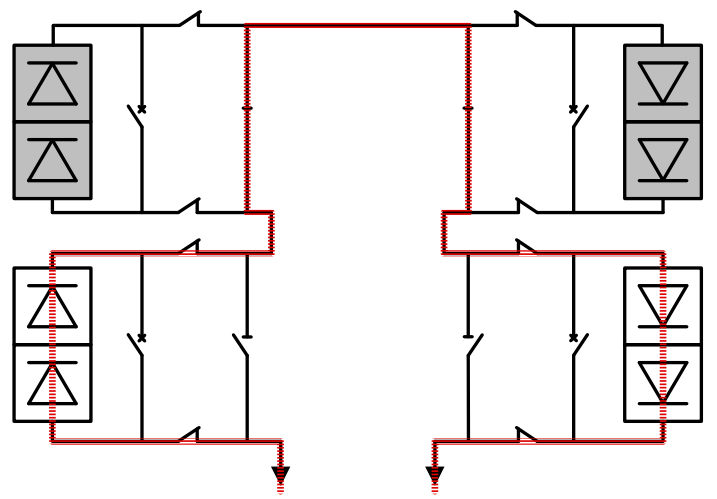

(c)

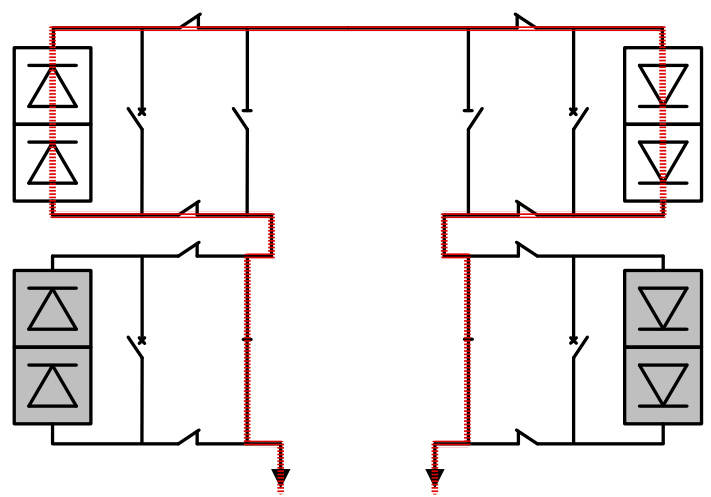

(b)

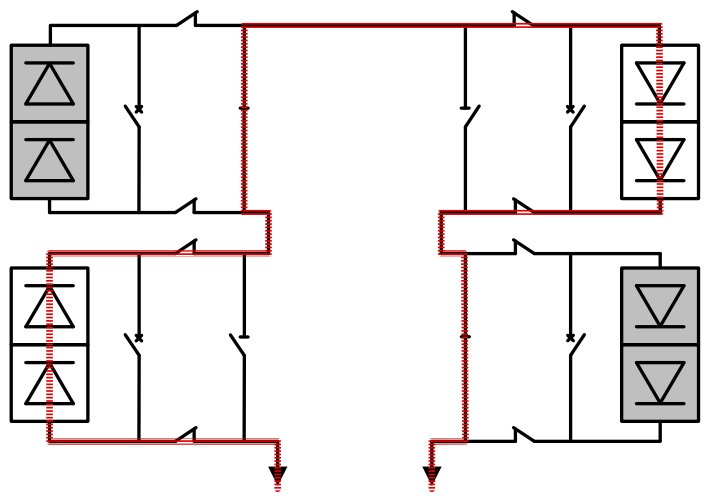

(d)

Figure 4. Possible operation modes of the positive pole of an LCC-UHVDC system. (a) Normal operation; (b) High-voltage (HV) valve-groups operation; (c) Low-voltage (LV) valve-groups operation; (d) Mixed valve-groups operation.

\section{Valve-Group Bypassing Strategy for LCC-UHVDC}

In this section, the full-voltage to half-voltage control strategy for LCC-UHVDC systems is proposed. The full-voltage to half-voltage operation can be achieved by controlling the firing angle $\alpha$ or extinction angle $\gamma$ of the valve-groups which need to be bypassed to a large degree (e.g., $90^{\circ}$ ). Then, the BPS and isolators will operate accordingly to achieve a smooth transition.

Figure 5 illustrates the sequence of bypassing the HV valve-group in the positive pole. In normal operating conditions, the current flows through the both HV and LV valve-groups, as shown in Figure 5a. The DC voltage of the HV valve-groups will start to decrease once the valve-groups receive the order to increase the $\alpha$ (or $\gamma$ ). The DC voltage of the LV LCC valve-group remain constant. The BPS will be closed once the DC voltage decreases to a minimum value (e.g., 0.1 p.u.) that the BPS can be closed, as shown in Figure 5b. Then, the HV valve-group will be blocked. At the same time, the bypass isolator (3) will be closed. During this process, the current will be fully transferred to the BPS and the bypass isolator (3), as shown in Figure 5c. The BPS will be opened once the isolator is fully closed. Then, the current will only flow through the isolator, as shown in Figure 5d. At last, the isolators (1) and (2) will be opened and the valve-group is fully isolated.

Figure 6 shows the proposed control block for the valve-groups to be bypassed. The function of the "in/out hold" is: the input is passed to the output when the hold (bypassing order) is 0; when a hold signal transition from 0 to 1 is detected, the output is held at that input sampled value. It means, in normal operation, the firing angle $\alpha$ or extinction angle $\gamma$ is directly sent to the valves. The $\alpha$ or $\gamma$ will be ramped up from the pre-change value with a specific ramping rate to $90^{\circ}$ once the bypassing order is received from the system upper level control. 


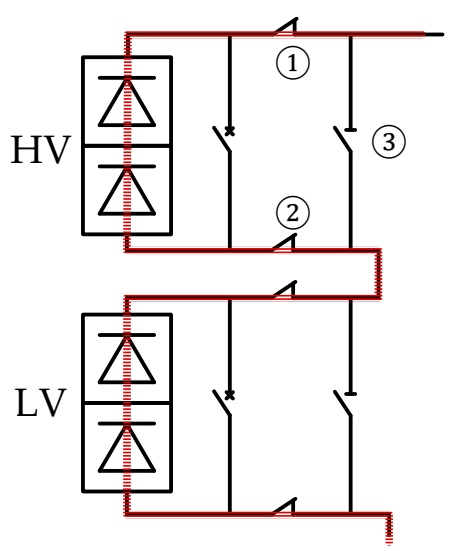

(a)

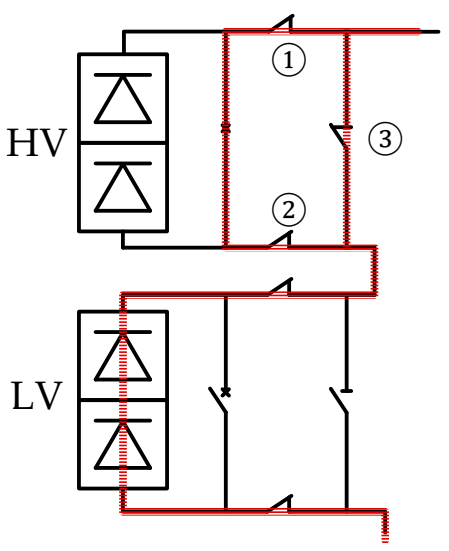

(c)

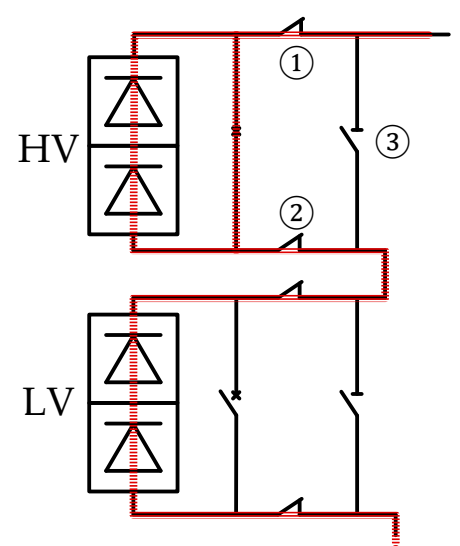

(b)

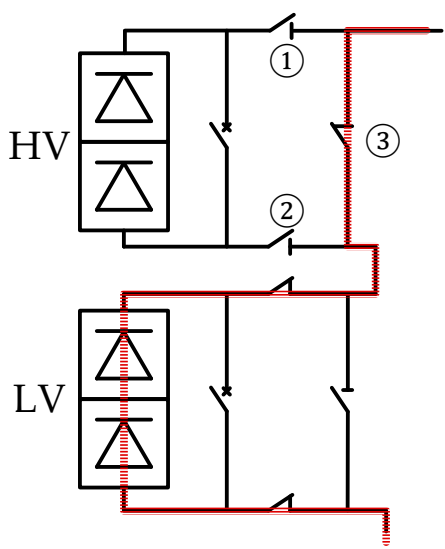

(d)

Figure 5. The sequence of bypassing the HV valve-group. (a) Normal operation; (b) BPS closed; (c) Valve blocked, isolator closed; (d) Half-voltage operation.

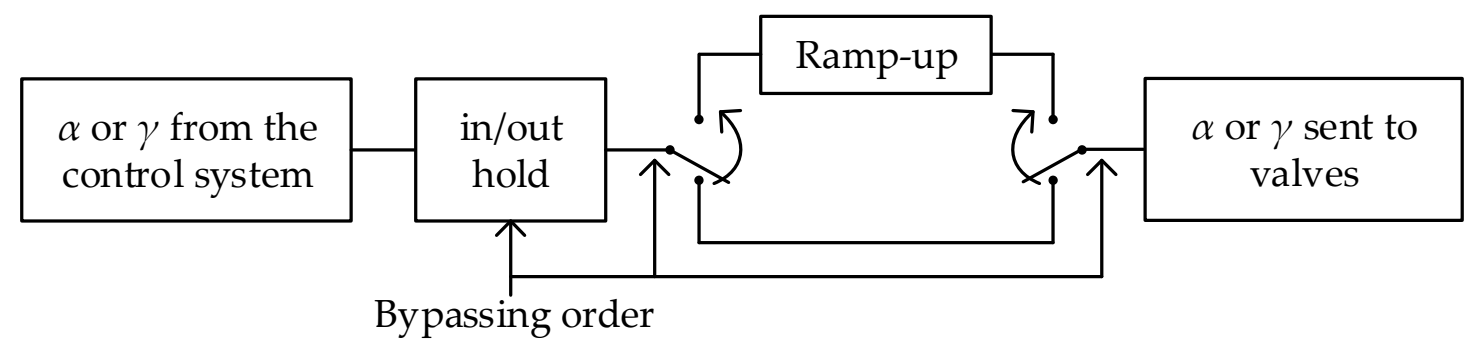

Figure 6. The valve-group bypassing control logic.

Take the system shown in Figure 1 as an example. The detailed sequences of bypassing the HV valve-groups are summarized below:

(1) The extinction angle $\gamma$ of the HV valve-group in the inverter will be ramped up to $90^{\circ}$ once a bypassing order is received from the system upper level control. At the same time, the bypassing order will be transmitted to the rectifier;

(2) The firing angle $\alpha$ of the HV valve-group in the rectifier will be ramped up to $90^{\circ}$ once the bypassing order is received;

(3) When the voltage of the HV valve-groups decrease to 0.1 p.u., the BPS is closed. Then, the valve-groups are blocked. At the same time, the bypass isolator will be closed;

(4) The BPS is opened once the bypass isolator is fully closed;

(5) The valve-group isolators are opened once the BPS is fully opened; 
(6) The full-voltage to half-voltage process completes after the above process.

It should be mentioned the above control sequences can also be applied to the $L V$ valve-group in the positive pole and the HV or LV valve-groups in the negative pole.

\section{Valve-Group Bypassing Strategy for Hybrid LCC/VSC UHVDC}

The full-voltage to half-voltage control strategies of hybrid LCC/MMC UHVDC systems will be different from the LCC-UHVDC systems due to the inherent characteristics of LCCs and MMCs. In addition, as the converter configurations of HB-MMCs and FB-MMCs are different, different control strategies should be considered for LCC/HB-MMC and LCC/FB-MMC UHVDC systems.

\subsection{The VSC in the Hybrid System is Half-Bridge Modular Multilevel Converter (HB-MMC)}

Figure 7 shows the positive pole of an LCC/HB-MMC HVDC system. The DC voltage controllability of the HB-MMC is limited within $V_{a c}$ to $V_{d c}$, where $V_{a c}$ is the converter valve-side line voltage and $V_{d c}$ is the DC side pole-to-ground voltage. Therefore, it cannot adjust the DC voltage from $V_{d c}$ to 0 through its DC voltage controller. In order to bypass the valve-groups, the DC current needs to be firstly reduced to a minimum value (0.1 p.u.). Then, both the HV and LV LCCs and the HV MMC need to be blocked. The LV MMC can keep operating as a static synchronous compensator (STATCOM) during the process.

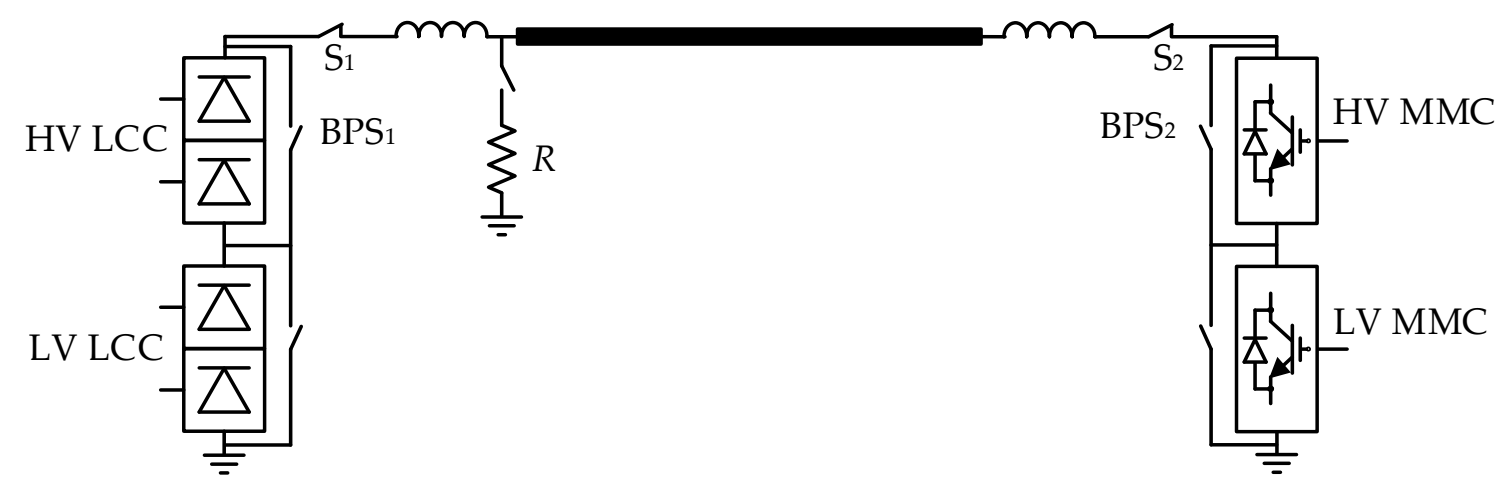

Figure 7. The positive pole of an LCC/half-bridge (HB)-MMC UHVDC system.

Although the current in the DC line becomes zero after blocking the valve-groups, the energy stored in the DC line will make its voltage remain at a high value. The DC voltage of the DC line may take a long time to naturally decay to zero. Therefore, $\mathrm{BPS}_{1}$ and $\mathrm{BPS}_{2}$ cannot be closed directly after blocking the converters because the LV valve-groups may be damaged by the DC line residual voltage. In order to speed up the voltage decaying process, a discharging resistor is employed to achieve a fast de-energization. Before inserting the discharging resistor $R$, the DC side switches $S_{1}$ and $S_{2}$ are opened to isolate the converters from the DC line. Then, the DC line will discharge through the resistor quickly. After opening the switches $S_{1}$ and $S_{2}$, the BPS $S_{1}$ and BPS $S_{2}$ and isolators can operate to bypass the HV valve-groups of the LCC and MMC.

The system can restore soon after bypassing the valve-groups. The discharging resistor $R$ will be firstly removed. Then, the DC switch $S_{1}$ will be closed. The LV LCC will be deblocked to charge the DC line. The DC switch $S_{2}$ will be closed when the DC line voltage reaches to the DC voltage of the LV MMC. The power transmission will be interrupted for a short time during this full-voltage to half-voltage process.

The detailed sequences of bypassing the HV valve-groups are summarized below:

(1) Reduce the DC current to a minimum value (0.1 p.u.) once a bypassing order is received from the system upper level control; 
(2) Block the HV and LV LCCs and the HV MMC valve-groups once the DC current is reduced to the target value;

(3) The DC terminal switches are tripped to isolate the converters from the DC line; Then, the discharging resistor is inserted; The HV valve-groups are bypassed during this process;

(4) The discharging resistor is removed once the DC line is fully de-energized;

(5) The LV LCC is deblocked to charge the DC line once its DC side switch is re-closed;

(6) The LV MMC's DC side switch is closed once the DC line voltage reaches to its DC terminal voltage;

(7) The full-voltage to half-voltage process completes after the above process.

\subsection{The VSC in the Hybrid System is Full-Bridge Modular Multilevel Converter (FB-MMC)}

Differing from HB-MMC, FB-MMC has the capability to control the DC voltage from $V_{d c}$ to $-V_{d c}$ [26]. Based on the modulation and control principle of MMC, the DC voltage of a FB-MMC can be given as

$$
V_{d c}=\sum_{i=1}^{N}\left(S_{p i} V_{c a p}\right)+\sum_{i=1}^{N}\left(S_{n i} V_{c a p}\right)
$$

where $V_{c a p}$ is the capacitor voltage of a sub-module (SM), $S_{p i}$ and $S_{n i}$ are the switching function of the SMs in the upper arms and lower arms. The switching function has three states. For instance, the output voltage of the SM will be $V_{\text {cap }}$ when $S_{i}=1$; the output voltage is 0 when $S_{i}=0$ and the output voltage is $-V_{\text {cap }}$ when $S_{i}=-1$. In order to achieve a stable online valve-group bypassing, the following modulation strategy is employed. The number of inserted SMs in the upper and lower arms is shown below:

$$
\left\{\begin{array}{l}
N_{\text {up }}=\frac{0.5 V_{\text {dcref }}-V_{\text {acref }}}{V_{\text {rrated }}} \\
N_{\text {down }}=\frac{0.5 V_{\text {cref }}+V_{\text {acref }}}{V_{\text {crated }}}
\end{array}\right.
$$

where $N_{\text {up }}$ and $N_{\text {down }}$ are the inserted SM number for the upper and lower arms, $V_{d c r e f}$ is the DC voltage reference which will be decreased during the full-voltage to half-voltage operation with a ramp-down rate, $V_{\text {acref }}$ is the MMC output ac voltage reference calculated from the control system, $V_{\text {crated }}$ is the rated SM capacitor voltage. Then the DC voltage of the MMC is

$$
V_{d c}=\left(N_{\text {up }}+N_{\text {down }}\right) V_{\text {cap }}=\left(\frac{0.5 V_{\text {dcref }}-V_{\text {acref }}}{V_{\text {crated }}}+\frac{0.5 V_{\text {dcref }}+V_{\text {acref }}}{V_{\text {crated }}}\right) V_{\text {cap }}=\left(\frac{V_{\text {dcref }}}{V_{\text {crated }}}\right) V_{\text {cap }}
$$

From (3), the DC voltage can be controlled by regulating the DC reference, the whole SM capacitor voltage $V_{\text {cap }}$ remains stable. The DC voltage outer loop controller is shown in Figure 8. To achieve an online valve-group bypass, the target valve-group of the FB-MMC will start to decrease the DC voltage. At the same time, the target valve-group of the LCC will be controlled to follow the voltage drop. The power transmission will not be interrupted during this full-voltage to half-voltage process.

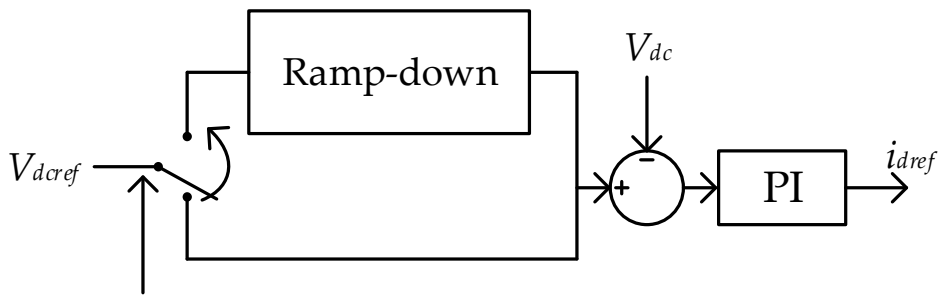

Bypassing order

Figure 8. DC voltage outer loop controller of the full-bridge (FB)-MMC.

The detailed sequences of bypassing the HV valve-groups are summarized below: 
(1) The DC voltage of the HV valve-group of the FB-MMC will be controlled to ramp down to a minimum value ( 0.1 p.u.) once a bypassing order is received from the system upper level control. At the same time, the bypassing order will be transmitted to the rectifier;

(2) The firing angle $\alpha$ of the HV valve-group in the rectifier will be ramped up to follow the voltage decrease controlled by the FB-MMC;

(3) When the voltage of the HV valve-groups decrease to 0.1 p.u., the BPS is closed. Then, the valve-groups are blocked. At the same time, the bypass isolator will be closed;

(4) The BPS is opened once the bypass isolator is fully closed;

(5) The valve-group isolators are opened once the BPS is fully opened;

(6) The full-voltage to half-voltage process completes after the above process.

\section{Power Rescheduling Strategy for Full-Voltage to Half-Voltage Operation}

After completing the process of full-voltage to half-voltage operation, the system may lose some power transmission capability. In order to minimize the load-shedding caused by the half-voltage operation, a power rescheduling strategy has to be designed.

Assuming the power transmitted in each valve-group is equal and the value is $P_{0}$ before the full-voltage to half-voltage process, therefore, the power transmitted in each pole is $2 \mathrm{P}_{0}$ and the total power of the system is $4 \mathrm{P}_{0}$. The rated power of each valve-group is $\mathrm{P}_{\text {rated }}$. Therefore, $\mathrm{P}_{0} \leq \mathrm{P}_{\text {rated }}$. The detailed sequences of the power rescheduling are summarized below:

(1) If $\mathrm{P}_{0} \leq \frac{1}{2} \mathrm{P}_{\text {rated }}$, the new power reference for the half-voltage operating valve-group will be set as $2 \mathrm{P}_{0}$. The power reference for the full-voltage operating pole is not changed. In this case, there is no power loss.

(2) If $\frac{1}{2} \mathrm{P}_{\text {rated }}<\mathrm{P}_{0} \leq \frac{3}{4} \mathrm{P}_{\text {rated }}$, the new power reference for the half-voltage operating valve-group will be set as $P_{\text {rated. }}$ In this case, the increased power of the half-voltage valve-group is $\left(P_{\text {rated }}-P_{0}\right)$, the lost power is $\mathrm{P}_{0}-\left(\mathrm{P}_{\text {rated }}-\mathrm{P}_{0}\right)=\left(2 \mathrm{P}_{0}-\mathrm{P}_{\text {rated }}\right)$ which can be undertaken by the full-voltage operating pole. It is known the original power in the full-voltage operating pole is $2 \mathrm{P}_{0}$. As $\mathrm{P}_{0} \leq \frac{3}{4} \mathrm{P}_{\text {rated }}$, therefore $\left(2 \mathrm{P}_{0}-\mathrm{P}_{\text {rated }}\right)+2 \mathrm{P}_{0}=\left(4 \mathrm{P}_{0}-\mathrm{P}_{\text {rated }}\right) \leq 2 \mathrm{P}_{\text {rated }}$. Therefore, the new power reference for the full-voltage operating pole is set to $\left(4 \mathrm{P}_{0}-\mathrm{P}_{\text {rated }}\right)$. In this case, power loss of the system is 0 .

(3) If $\frac{3}{4} \mathrm{P}_{\text {rated }}<\mathrm{P}_{0} \leq \mathrm{P}_{\text {rated }}$, the new power reference for the half-voltage operating valve-group will be set as $P_{\text {rated }}$. The power reference for the full-voltage operating valve-group will be set as $2 \mathrm{P}_{\text {rated }}$. In this case, the power loss in the system is $\left(4 \mathrm{P}_{0}-3 \mathrm{P}_{\text {rated }}\right)$.

The power rescheduling strategy is summarized in Table 1.

Table 1. Power rescheduling strategy.

\begin{tabular}{cccc}
\hline $\begin{array}{c}\text { Initial Power of Each } \\
\text { Valve-Group }\end{array}$ & $\begin{array}{c}\text { Power Reference for } \\
\text { Half-Voltage Pole }\end{array}$ & $\begin{array}{c}\text { Power Reference for } \\
\text { Full-Voltage Pole }\end{array}$ & $\begin{array}{c}\text { System } \\
\text { Power Loss }\end{array}$ \\
\hline $\mathrm{P}_{0} \leq \frac{1}{2} \mathrm{P}_{\text {rated }}$ & $2 \mathrm{P}_{0}$ & $2 \mathrm{P}_{0}$ & 0 \\
$\frac{1}{2} \mathrm{P}_{\text {rated }}<\mathrm{P}_{0} \leq \frac{3}{4} \mathrm{P}_{\text {rated }}$ & $\mathrm{P}_{\text {rated }}$ & $4 \mathrm{P}_{0}-\mathrm{P}_{\text {rated }}$ & 0 \\
$\frac{3}{4} \mathrm{P}_{\text {rated }}<\mathrm{P}_{0} \leq \mathrm{P}_{\text {rated }}$ & $\mathrm{P}_{\text {rated }}$ & $2 \mathrm{P}_{\text {rated }}$ & $4 \mathrm{P}_{0}-3 \mathrm{P}_{\text {rated }}$ \\
\hline
\end{tabular}

\section{Case Studies}

The above analysis and proposed control strategies are verified in the LCC and hybrid LCC /MMC UHVDC systems built in PSCAD/EMTDC. It should be mentioned that a simulation time step of $10 \mu \mathrm{s}$ is used to ensure the accuracy of the simulation. 


\subsection{LCC-UHVDC Point-to-Point Link}

$\mathrm{A} \pm 800 \mathrm{kV}, 5 \mathrm{GW}$ LCC-UHVDC system has been built in PSCAD/EMTDC. The system configuration is shown in Figure 1. The parameters are modified based on the Xiangjiaba-Shanghai LCC-UHVDC project. The parameters of the converters, transformers, ac and DC side filters are given in Table 2 and shown in Figures A1 and A2 in the Appendix A. The Frequency Dependent DC overhead line model (dimensions and parameters) in PSCAD is illustrated in Figure A3 in the Appendix A as well. The DC link distance is set as $1450 \mathrm{~km}$. The HV valve-groups in the positive pole are bypassed as an example to achieve the full-voltage to half-voltage operation.

Table 2. System parameters.

\begin{tabular}{cc}
\hline Parameters & Real Value \\
\hline Capacity (MVA) & 5000 \\
Rated DC voltage $(\mathrm{kV})$ & \pm 800 \\
AC grid frequency $(\mathrm{Hz})$ & 50 \\
Rated AC voltages $(\mathrm{kV})$ & $525(\mathrm{Rec})$ \\
& $500(\mathrm{Inv})$ \\
Transformer ratios $(\mathrm{kV} / \mathrm{kV})$ & $525 / 185(\mathrm{Rec})$ \\
& $500 / 175(\mathrm{Inv})$ \\
Transformer capacity per valve (MVA) & $703.125(\mathrm{Rec})$ \\
Transformer leakage inductance (p.u.) & $625(\mathrm{Inv})$ \\
\hline
\end{tabular}

Figure 9 illustrates the system dynamics during the full-voltage to half-voltage operation. The initial DC current (power) was set as $0.8 \mathrm{p} . \mathrm{u}$. The inverter received bypassing signal at $t=1 \mathrm{~s}$. A $10 \mathrm{~ms}$ delay is set for the rectifier to receive the bypassing signal to represent the communication delay. $V_{d c R e c}$ is the DC terminal voltage of the rectifier. As shown in Figure 9a, $V_{d c R e c}$ started to drop once the firing angle is controlled to increase to $90^{\circ}$. The $V_{d c R e c M i d}$ is the voltage between the HV and $\mathrm{LV}$ valve-groups of the rectifier. It can be seen that the $V_{d c R e c M i d}$ and the DC current $I_{d c}$ were almost not affected during the full-voltage to half-voltage control process. It is because the voltage reduction of the HV valve-group does not affect the voltage of the LV valve-group which can keep controlling the DC current constantly. According to the proposed power reschedule strategy, the current (power) was then set to 1 p.u. when the BPS and isolators successfully operated to isolate HV valve-groups. The power transmission is not interrupted during the full-bridge to half-bridge process. Figure $9 b, c$ show the firing angles and extinction angles of the rectifier and inverter, respectively. The firing angles and extinction angles of the HV valve-groups were controlled to ramp up once the bypassing signals were received. It should be mentioned that the HV valve-groups may have been blocked before their firing or extinction angle reaches to $90^{\circ}$.

Figure 10a shows the voltage and current of the negative pole. The firing angle of the rectifier of the negative pole is shown in Figure 10b. According to the proposed power reschedule strategy, the current (power) was increased to 1 p.u. at $t=1.6 \mathrm{~s}$ to compensate the power loss caused by the half-voltage operation of the positive pole. The power loss of the whole system is $6.25 \%$ of its initial power. 

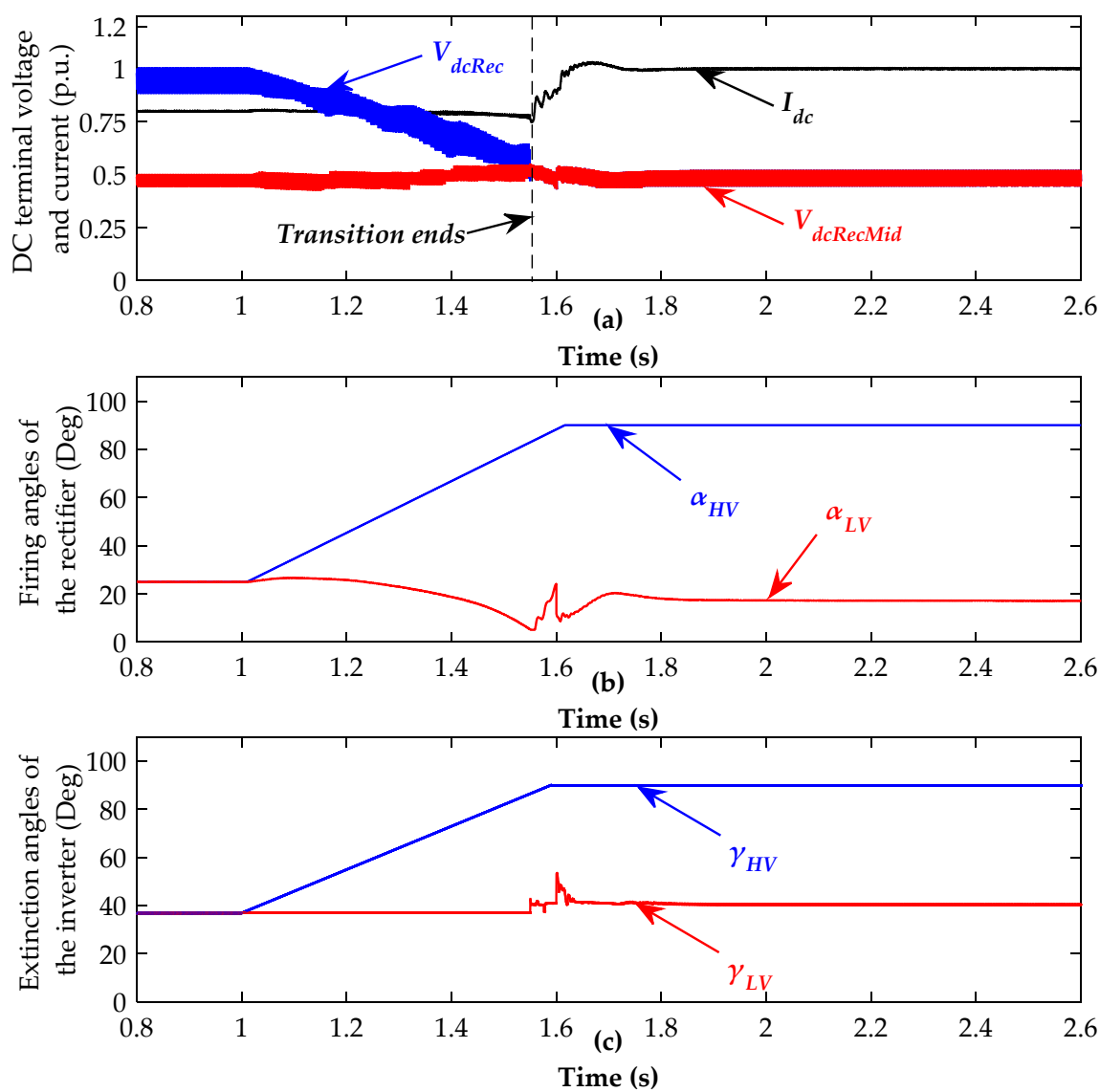

Figure 9. System dynamics during the full-voltage to half-voltage operation of the LCC-UHVDC link. (a) DC terminal voltage and current of the sending end; (b) Firing angles of the LV and HV valve-groups of the sending end; (c) Extinction angles of the LV and HV valve-groups of the receiving end.
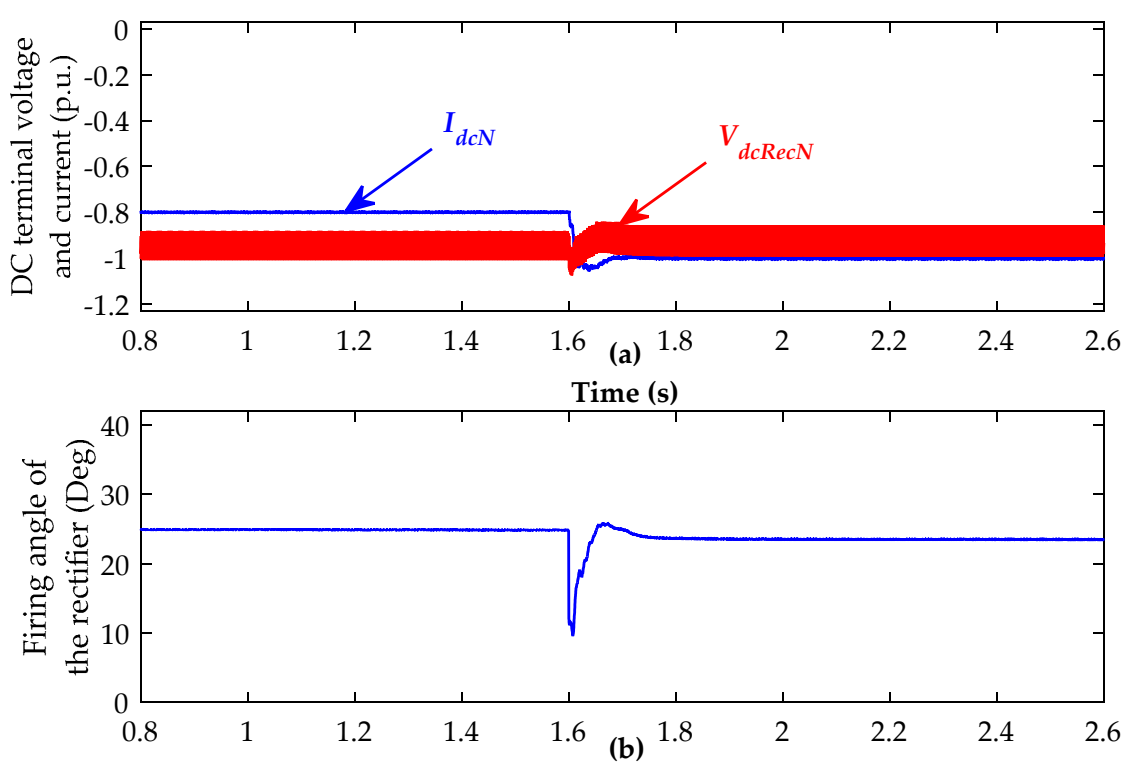

Time (s)

Figure 10. System dynamics of the negative pole. (a) DC terminal voltage and current of the sending end; (b) Firing angle of the sending end. 


\subsection{Hybrid LCC/HB-MMC UHVDC Point-to-Point Link}

$\mathrm{A} \pm 800 \mathrm{kV}, 5 \mathrm{GW}$ LCC /HB-MMC UHVDC system has been built in PSCAD. The inverter in the previous case is replaced by a HB-MMC with HV and LV valves. The LCC parameters and DC line are the same with the previous case. The parameters of the MMC are shown in Table 3.

Table 3. Parameters of the HB-MMC.

\begin{tabular}{cc}
\hline Parameters & Real Value \\
\hline Capacity (MVA) & 5000 \\
Rated DC voltage (kV) & \pm 800 \\
AC grid frequency (Hz) & 50 \\
Rated AC voltages (kV) & 500 \\
Transformer ratios (kV/kV) & $500 / 260$ \\
Transformer capacity per valve (MVA) & 1250 \\
Transformer leakage inductance (p.u.) & 0.14 \\
Number of SM & 167 \\
SM capacitor (mF) & 18 \\
\hline
\end{tabular}

Figure 11 illustrates the dynamic performance of the system. The initial DC current (power) was set as 0.8 p.u.. The DC current started to reduce to 0.1 p.u. at $t=1 \mathrm{~s}$. Then, the HV and LV LCCs and the HV MMC were blocked at $t=1.2 \mathrm{~s}$. The DC switches at the two terminals of the DC line were tripped after blocking the converters. Then, the discharging resistor was inserted until the DC circuit voltage decayed to zero. During this period, the HV valve-groups of the LCC and MMC were isolated by their bypass switches and isolators. The LV LCC's DC side switch was re-closed at $t=1.4 \mathrm{~s}$. The controller of LV LCC was reset (the initial firing angle was $90^{\circ}$ ) and deblocked at $t=1.41 \mathrm{~s}$. The LV MMC's DC side switch was closed at $t=1.45 \mathrm{~s}$. Then, the current was controlled to increase to 1 p.u.
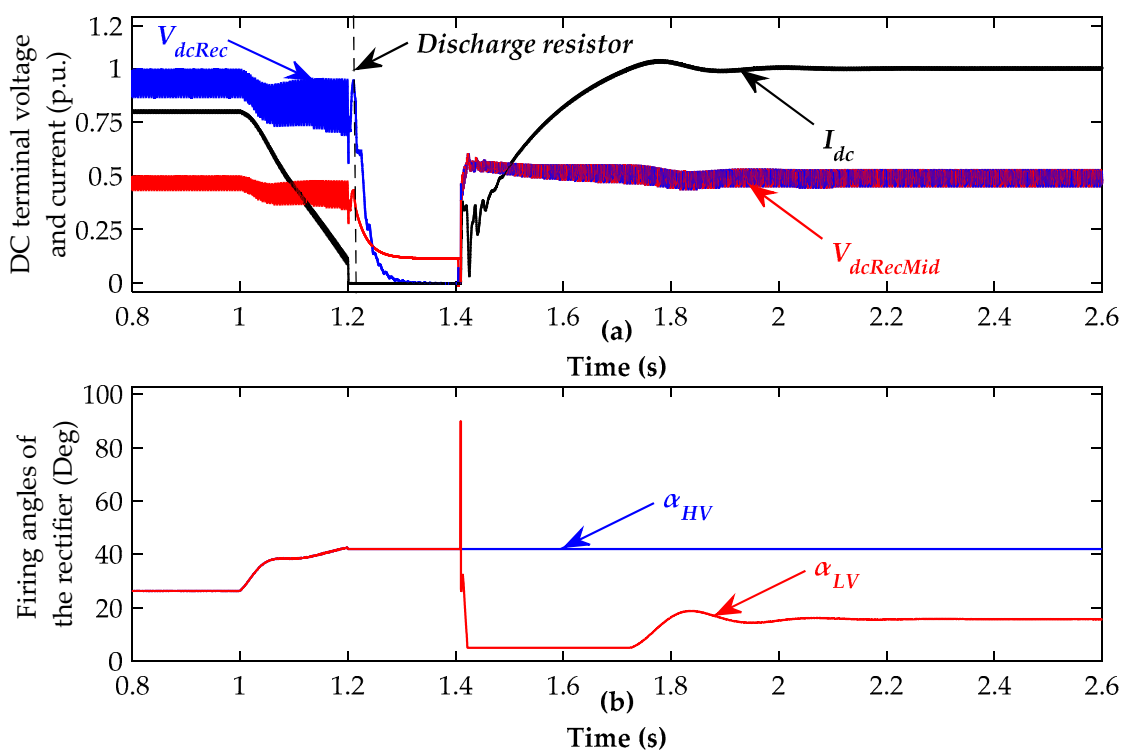

Figure 11. System dynamics during the full-voltage to half-voltage operation of the Hybrid LCC/HB-MMC UHVDC link. (a) DC terminal voltage and current of the sending end; (b) Firing angles of the $\mathrm{LV}$ and $\mathrm{HV}$ valve-groups of the sending end.

\subsection{Hybrid LCC/FB-MMC UHVDC Point-to-Point Link}

$\mathrm{A} \pm 800 \mathrm{kV}, 5 \mathrm{GW}$ LCC /FB-MMC UHVDC system has been built in PSCAD. The inverter in the previous case is replaced by an FB-MMC with HV and LV valves. The parameters of the FB-MMC is the same with the HB-MMC in the previous case. 
Figure 12 illustrates the dynamic performance of the system. The initial DC current (power) was set as 0.8 p.u.. The DC voltage controller of the HV FB-MMC started to reduce the DC voltage at $t=1 \mathrm{~s}$. At the same time, the firing angle $\left(\alpha_{H V}\right.$ in the figure) of the HV LCC started to increase. During this period, the controller of the LV LCC was operating to control the DC current to be constant. The HV LCC and MMCs were blocked when the DC output voltage of the HV LCC reduced to 0.1 p.u. (0.6 p.u. of the DC line voltage). Then the bypass switches and isolators operated to isolate the HV LCC valve-groups. Then, the current was controlled to increase to 1 p.u. The power transmission is not interrupted during the full-bridge to half-bridge process.

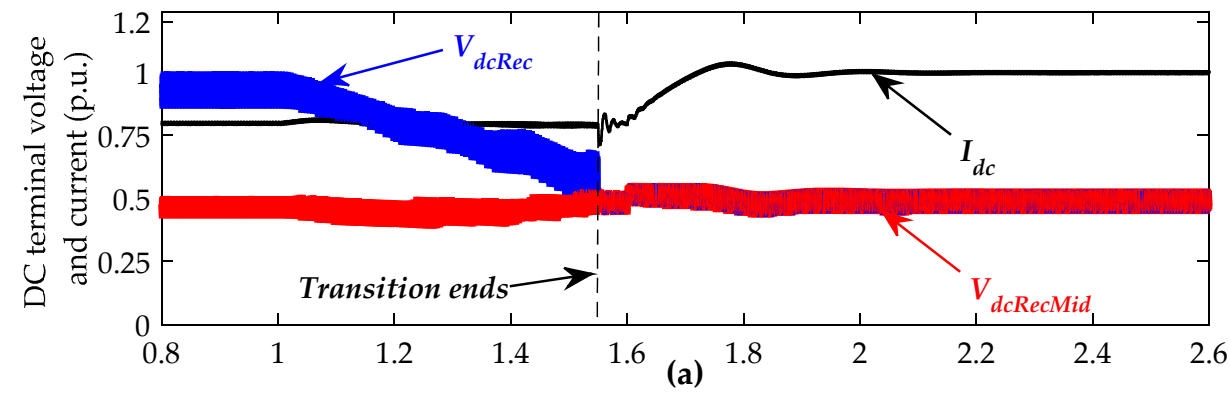

Time (s)

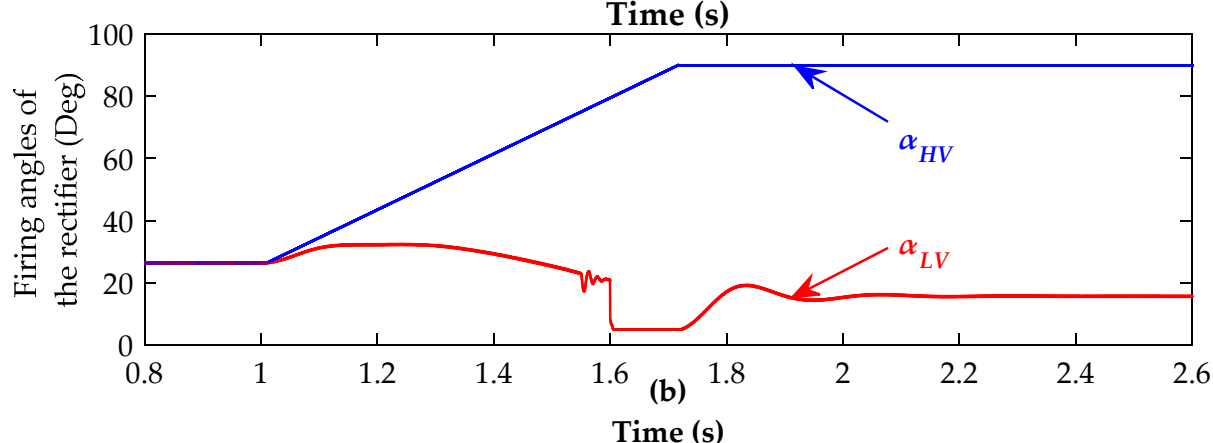

Figure 12. System dynamics during the full-voltage to half-voltage operation of the Hybrid LCC/FB-MMC UHVDC link. (a) DC terminal voltage and current of the sending end; (b) Firing angles of the LV and $\mathrm{HV}$ valve-groups of the sending end.

\section{Conclusions}

This paper investigated the control strategies of full-voltage to half-voltage operation for LCC and hybrid LCC/MMC UHVDC systems. The full-voltage to half-voltage process can be achieved within several hundred milliseconds by the proposed strategies without inducing large transient overvoltage and overcurrent. A fast full-voltage to half-voltage operation for a hybrid LCC/HB-MMC UHVDC system needs the help of a DC side discharging resistor. Therefore, it will experience a short time power outage during the full-voltage to half-voltage process. While the LCC and LCC/FB-MMC UHVDC systems can be achieved online valve-group bypassing without interrupting the power transmission. Moreover, a power reschedule strategy has been proposed to achieve a minimum power loss caused by the half-voltage operation. The proposed strategies have been verified through time-domain simulations conducted in PSCAD/EMTDC. The studies can be a useful guidance for the operation and control for future UHVDC systems

Author Contributions: The authors contribute to this paper equally.

Funding: The authors acknowledge the funding from Science and Technology Project of the State Grid Corporation of China, "HVDC Systems/Grids for Transnational Interconnections", project number: SGTYHT/16-JS-198.

Conflicts of Interest: The authors declare no conflict of interest. 
Appendix A

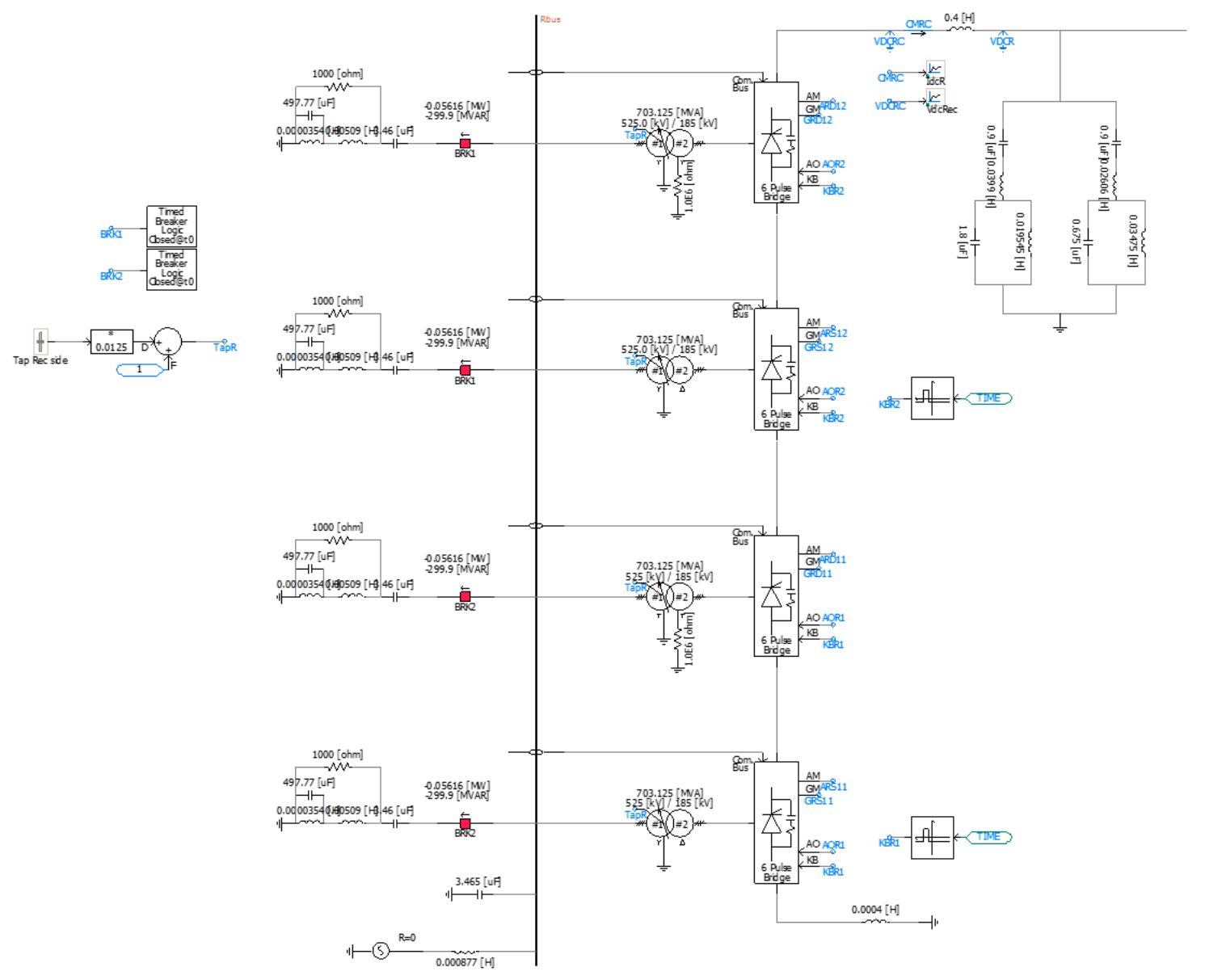

Figure A1. The sending end LCC PSCAD model. 


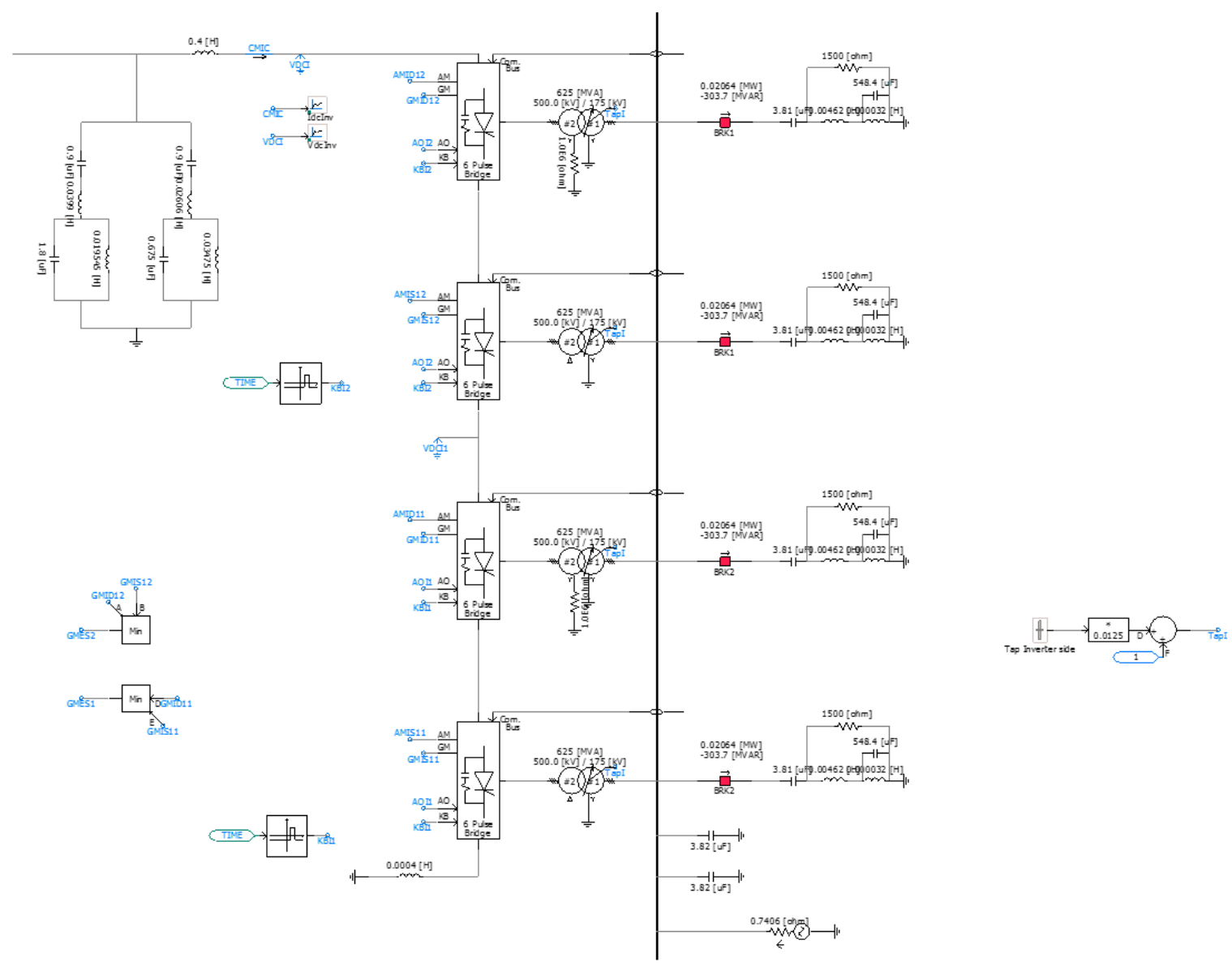

Figure A2. The receiving end LCC PSCAD model.

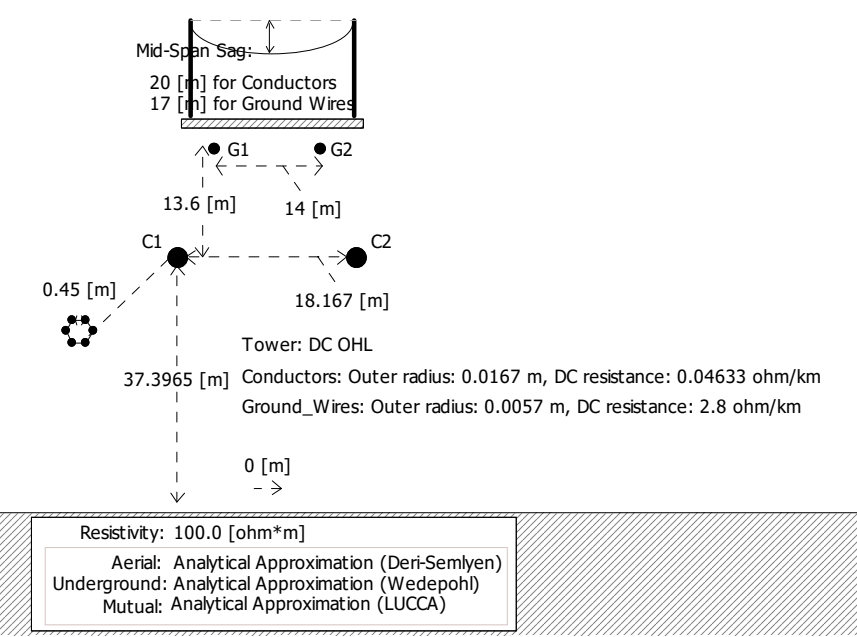

Figure A3. The dimensions and parameters of the $\pm 800 \mathrm{kV}$ overhead line model in PSCAD.

\section{References}

1. Wang, Y.; Wen, W.; Wang, C.; Liu, H.; Zhan, X.; Xiao, X. Adaptive Voltage Droop Control of Multiterminal VSC-HVDC Systems for DC Voltage Deviation and Power Sharing. IEEE Trans. Power Del. 2019, 34, 169-176. [CrossRef]

2. Li, G.; Liang, J.; Ugalde-Loo, C.E.; Coventry, P.; Rimez, J. Dynamic interactions of DC and AC grids subject to DC faults. In Proceedings of the 2016 IEEE 8th International Power Electronics and Motion Control Conference (IPEMC-ECCE Asia), Hefei, China, 22-26 May 2016; pp. 2627-2633. 
3. Bucher, M.K.; Franck, C.M. Contribution of Fault Current Sources in Multiterminal HVDC Cable Networks. IEEE Trans. Power Del. 2013, 28, 1796-1803. [CrossRef]

4. Li, G.; Li, C.; van Hertem, D. HVDC technology overview. In HVDC Grid: For Offshore and Supergrid of the Future; Wiley-IEEE: Piscataway, NJ, USA, 2016; Chapter 3; pp. 45-78.

5. Joseph, T.; Ugalde-Loo, C.E.; Liang, J.; Coventry, P.F. Asset Management Strategies for Power Electronic Converters in Transmission Networks: Application to Hvdc and FACTS Devices. IEEE Access 2018, 6, 21084-21102. [CrossRef]

6. Barnes, M.; van Hertem, D.; Teeuwsen, S.P.; Callavik, M. HVDC Systems in Smart Grids. Proc. IEEE 2017, 105, 2082-2098. [CrossRef]

7. World's Biggest Ultra-High Voltage Line Powers Up Across China. Available online: https: / / www.bloomberg.com/news/articles/2019-01-02/world-s-biggest-ultra-high-voltage-line-powers-upacross-china (accessed on 15 January 2019).

8. Perez, M.A.; Bernet, S.; Rodriguez, J.; Kouro, S.; Lizana, R. Circuit Topologies, Modeling, Control Schemes, and Applications of Modular Multilevel Converters. IEEE Trans. Power Electron. 2015, 30, 4-17. [CrossRef]

9. Li, G.; Liang, J.; Ma, F.; Ugalde-Loo, C.E.; Liang, H. Analysis of Single-Phase-to-Ground Faults at the Valve-Side of HB-MMCs in HVDC Systems. IEEE Trans. Ind. Electron. 2019, 66, 2444-2453. [CrossRef]

10. Kouro, S.; Malinowski, M.; Gopakumar, K.; Pou, J.; Franquelo, L.G.; Wu, B.; Rodriguez, J.; Perez, M.A.; Leon, J.I. Recent Advances and Industrial Applications of Multilevel Converters. IEEE Trans. Ind. Electron. 2010, 57, 2553-2580. [CrossRef]

11. TBEA. The World's First-ever $\pm 800 \mathrm{kV}$ Modular Multilevel Converter Valve has been Developed. Available online: http:/ / en.tbeaenergy.com/content/details144_1804.html (accessed on 15 January 2018).

12. RXPE. RXHK Awarded World's Largest VSC HVDC Converter Contract. Available online: http:/ / www. rxpe.co.uk/corporate/news/worlds-largest-vsc-hvdc-converter-order/ (accessed on 15 January 2018).

13. Song, J. Analysis of Hybrid LCC-VSC HVDC Transmission Systems. Master's Thesis, Universitat Politècnica de Catalunya UPC, Barcelona, Spain, 2018.

14. Lebre, J.R.; Portugal, P.M.M.; Watanabe, E.H. Hybrid HVDC ( $\left.\mathrm{H}^{2} \mathrm{VDC}\right)$ System Using Current and Voltage Source Converters. Energies 2018, 11, 1323. [CrossRef]

15. Li, G.; Liang, J.; Joseph, T.; An, T.; Szechtman, M.; Andersen, B.; Zhuang, Q. Start-up and Shut-down Strategies of Hybrid LCC/VSC DC Grids. In Proceedings of the 2018 2nd IEEE Conference on Energy Internet and Energy System Integration (EI2), Beijing, China, 20-22 October 2018; pp. 1-5.

16. Mohamed Haleem, N.; Rajapakse, A.D.; Gole, A.M.; Fernando, I.T. Investigation of Fault Ride-Through Capability of Hybrid VSC-LCC Multi-Terminal HVDC Transmission Systems. IEEE Trans. Power Del. 2019, 34, 241-250. [CrossRef]

17. Li, G.; Liang, J.; Joseph, T.; An, T. Feasibility and Reliability Analysis of LCC DC Grids and LCC/VSC Hybrid DC Grids. IEEE Access 2019. [CrossRef]

18. Ying, H.; Weihuang, H.; Ming, L.; Tao, L. Steady-state control strategy of multi-terminal hybrid UHVDC. In Proceedings of the 2017 19th European Conference on Power Electronics and Applications (EPE'17 ECCE Europe), Warsaw, Poland, 11-14 September 2017; pp. 1-10.

19. Liu, Z.; Yu, J.; Guo, X.; Sun, T.; Zhang, J. Survey of technologies of line commutated converter based high voltage direct current transmission in China. CSEE J. Power Energy Syst. 2015, 1, 1-8. [CrossRef]

20. Rao, H.; Xu, S.; Zhou, Y.; Zhu, Z. Research on Main Circuit Scheme of VSC-UHVDC. Southern Power Syst. Technol. 2017, 11, 1-4.

21. Xie, K.; Hu, B.; Singh, C. Reliability Evaluation of Double 12-Pulse Ultra HVDC Transmission Systems. IEEE Trans. Power Del. 2016, 31, 210-218.

22. Vithayathil, J.J. Bypass operation in bridge convertors for high-voltage d.c. transmission. Proc. IEEE 1965, 112, 359-365.

23. Machida, T.; Yoshida, Y.; Fujii, N.; Yokoyama, K. Bypass control system for high-voltage dc converter using semiconductor control rectifiers. U.S. Patent 3,636,431, 18 January 1972.

24. Li, Y.; Huang, L.; Hong, C.; Li, X. Analysis on the Strategy of Block/Deblock Dual 12-Pulse Valve Groups in \pm 800 kV DC Transmission System. Southern Power Syst. Technol. 2010, 4, 21-25. 
25. Li, D.; Wang, Y.; Ding, L.; Li, X.; Dai, H.; Su, G. Blocking and deblocking strategy of single UHVDC converter group under joint control mode of dual 12-pulse converter groups. Electr. Power Autom. Equip. 2014, 34, 148-154.

26. Yu, L.; Guo, C.; Zhao, C.; Xu, J.; An, N.; Hu, X. Power Reversal of Hybrid HVDC System. In Proceedings of the 11th IET International Conference on AC and DC Power Transmission, Birmingham, UK, 10-12 February 2015; pp. 1-6. 